\title{
EDUCAÇÃO E DEMOCRACIA: PERSPECTIVA EMANCIPATÓRIA A PARTIR DA FILOSOFIA SOCIAL DE JOHN DEWEY
}

\section{Guilherme Perez Cabra ${ }^{1}$}

\section{Resumo}

O objetivo do presente artigo é apreender a filosofia social de John Dewey como referencial hermenêutico para a leitura e a prática enriquecidas do direito humano à educação, no âmbito do Estado Democrático de Direito. Realiza, para tanto, em termos metodológicos, pesquisa bibliográfica, revendo as principais obras do autor sobre a temática. No âmbito de uma proposta pragmatista de "reconstrução" filosófica, educação e democracia são concebidas como experiências comunicativas indissociáveis na realização do projeto iluminista de emancipação. A democracia aparece, para além da dimensão político-institucional, como uma experiência comunitária de solução compartilhada de conflitos sociais. A educação remete ao processo contínuo de crescimento cognitivo e moral do sujeito, constituindo-se como aprendizagem, em interação dialógica, de hábitos reflexivos do pensar, agir e conviver. Envolve, por isso, uma experiência educativa, configurada pelos seguintes princípios: derivação dos conteúdos educacionais das experiências de vida; educação baseada em problemas; desenvolvimento progressivo dos conteúdos educacionais; interação dialógica; e pedagogia diretiva. Assim concebida, educação que conduz o indivíduo à autonomia moral-cognitivista, habilita-o, concomitantemente, à experiência comunitária e compartilhada que caracteriza a democracia.

Palavras-chave: Educação; democracia; discurso, filosofia social; John Dewey.

\section{INTRODUÇÃO}

A filosofia social de John Dewey (1859-1952) constitui, ainda hoje, referencial original e fecundo para a reflexão sobre as experiências comunicativas indissociáveis da educação e da democracia. Descortina hermenêutica jurídica que contribui com leitura enriquecida de sentidos, comprometida com a práxis da linguagem e com o potencial racional de aprendizagem moral-cognitiva que lhe é imanente.

Isso exige, contudo, antes de qualquer coisa, o óbvio não raro negado pela história: "a leitura e o estudo cuidadoso do que Dewey realmente disse" (BRUBACHER, 1961, p. 82). Afinal, no contexto da disputa ideológica que marcou o Século XX, o educador e filósofo do pragmatismo norte-americano foi envolvido em leituras distorcidas e reduções desatentas que partiam dos dois lados conflito. Da esquerda, irrogaram a Dewey, os mais exaltados, o rótulo de "filósofo da burguesia imperialista" (MENDONÇA et AL., 2006, p. 100). Pelo menos,

\footnotetext{
${ }^{1}$ Doutor em Filofosia e Teoria Geral do Direito pela Universidade de São Paulo (USP). Professor de Introdução ao Estudo do Direito e Direito Constitucional na PUC-Campinas. E-mail: gpcabral@gmail.com
} 
um "elitista ingênuo" (GADOTTI, 2002, p. 143). No lado oposto, à direita, no final dos anos 1950, sua filosofia educacional, confundida com o não-diretivismo, foi alvo de críticas conservadoras, acusada de complacência excessiva e ausência de disciplina (BRUBACHER, 1961, p. 61 e 62). Antes mesmo de sua morte, o pensamento deweyano ingressava num período de esquecimento, sendo severamente restringido nas universidades de seu país (RORTY, 1996, p. 241; JOAS, 1993, p.02).

Dewey não foi "pessoalmente responsável por todos os pecados e atribulações", vividos pelos Estados Unidos, na primeira metade do Século XX, ressaltou, com sarcasmo, H. Benjamin (BENJAMIN, 1960, p. 31). Na realidade, por lá, seu programa educacional jamais se enraizou, não havendo "maior erro do que supô-lo seguido e, ainda menos, dominante no sistema escolar norte-americano" (TEIXEIRA, 1959, p. 02).

A revisita ao pensamento do autor vale a pena. Acontece na tradição do pragmatismo, onde Richard Rorty o elege um dos filósofos mais importantes do século passado, destacando, em sua obra, a "mensagem historicista", que rompe com o "padrão cartesiano-kantiano" da filosofia moderna (RORTY, 1998, p. 16 e 19). E supera seu ambiente filosófico, influenciando os atuais debates sobre a democracia, desenvolvidos no âmbito da Escola Frankfurt, por Jürgen Habermas e Axel Honneth.

Dewey concebe a educação, na sociedade democrática, dentro de ampla proposta de "reconstrução" da filosofia. Apreende-a no horizonte de uma perspectiva crítica da modernidade, em que denuncia o descompasso entre o grande progresso técnico-científico e o débil desenvolvimento moral da humanidade (DEWEY, 1991, p. 175; DEWEY, 2004, p. 25).

A filosofia reconstruída deweyana tem a pretensão de nos equipar metodologicamente para a solução dos conflitos sociais e morais, concretamente experimentados no cotidiano. E propõe que isso seja feito por meio do exercício do pensar, absorvendo, para tanto, da ciência moderna, sua qualidade de uma disposição racional, metódica, investigativa, experimental e falibilista. Ao mesmo tempo, confere devida importância à linguagem: a ambiência dialética da constituição social da individualidade e da construção compartilhada da verdade e da moral (DEWEY, 1980, p. 29; DEWEY, 2004, p.v).

O caminho para a compreensão profunda desse programa filosófico passa por algumas formulações fundamentais. A teoria da experiência, definida como a interação contínua entre o sujeito e seu ambiente. Reflexo particular do meio social, o indivíduo (re)age sobre ele, alimentando a permanente reconstrução das experiências que tecem o processo de vida. (TEIXEIRA, 1980, p. 115; DEWEY, 2004, p. 49). A teoria do pensar, compreendido como a operação racional, eminentemente prática, de solução de problemas com que a pessoa se depara no curso da ação. Seu lugar é a experiência, servindo à sua compreensão e reconstrução inteligente (DEWEY, 1997, p. 12; DEWEY, 2004, p. 54). Por fim, o modelo de crescimento moral-cognitivo, no curso processo experiencial, em que a criança ingressa heteronomamente no mundo moral e pode superá-lo, abrindo-se 
à autonomia, intersubjetivamente concebida, na linha da disposição científica e comunicativa que funda a filosofia reconstruída (DEWEY, 2008, p. 12).

Tudo isso, dando forma à filosofia social de Dewey, consolida sua visão da democracia e da educação, intitulada "progressiva". A democracia, para além do momento político-institucional, constitui uma experiência social e moral de autodeterminação, a ambiência da emancipação. É um modo de vida ao qual corresponde a experiência comunitária de solução compartilhada de problemas de coordenação social, no espaço público (DEWEY, 1991, p. 83 e 148; DEWEY, 1989, p. 101; HONNETH, 1998, p. 775): solução que se realiza pelo medium do direito - o Estado democrático de direito -, e que se consolida, ao mesmo tempo, como momento central de sua constituição.

A educação, a florescer da experiência democrática e a promovê-la, dialeticamente, remete ao processo contínuo de crescimento cognitivo e moral do sujeito. É aprendizagem, em interação dialógica, de hábitos reflexivos do pensar, agir e conviver, a partir da solução de problemas. Possibilita, assim, ao educando, progressivamente, ampliar e adensar o significado de sua experiência, habilitando-o à direção, inteligente e cooperativa, do curso das experiências ulteriores (DEWEY, 1916, p. 89 e 90). É, nesses termos, direito humano fundamental, indispensável à democracia.

Dewey funde o método científico ao democrático. Consolidando-os como processos de busca cooperativa da verdade - e, do ponto de vista moral-cognitivista, da justiça - faz da educação e da democracia experiências absolutamente coladas, uma pressupondo a outra, no caminho da emancipação humana.

Seguindo esse percurso teórico, o objetivo do presente artigo é utilizar a filosofia social deweyana como referencial hermenêutico para a construção de uma "versão discursiva" e de uma práxis enriquecida do direito humano à educação, no âmbito do Estado Democrático de Direito. Debruça-se, destarte, sobre "projetos de sentido" que não podem mais do que refletir, dialeticamente, a complexa e conflituosa ambiência social da qual emergem (HESPANHA, 2009, p. 654; BITTAR, 2010, p. 125).

Faz-se isso, metodologicamente, por meio da pesquisa bibliográfica, centrada na leitura e revisão das principais obras de Dewey nos campos da sobre educação e democracia, auxiliada pelos estudos críticos de autores que se debruçaram sobre sua filosofia social.

\section{A FILOSOFIA SOCIAL DE JOHN DEWEY}

O programa deweyano de reconstrução filosófica parte do diagnóstico crítico dos descaminhos da razão moderna. Sua aplicação promoveu inegável progresso técnico-científico, mas promoveu, também, barbáries morais, com a exploração brutal da natureza e do próprio homem. Não foi acompanhada de avanços no que se refere à reflexão crítico sobre o valor da conduta humana, de modo que permanecemos incapazes de solucionar 
racional e dialogicamente nossas questões morais (DEWEY, 1991, p. 175; DEWEY, 2008, p. 09).

A filosofia reconstruída se volta, nesse cenário, à tarefa prática de enfrentamento e solução dos conflitos concretos, que afligem o homem na interação social (DEWEY, 2004, p. 44). É teoria moral-cognitivista, lidando com a conduta humana e o julgamento racional de seu valor (DEWEY, 1897, p. 01 e 02; DEWEY, 2008, p. 09).

Para tanto, em primeiro lugar, tem de romper com a metafisica, da qual, para Dewey, a filosofia moderna não conseguiu se desvencilhar. Opõe-se ao dualismo platônico, recusando determinismos históricos e qualquer fundamento seguro em que se possa apoiar, a priori e metafisicamente, a verdade, a moral, a justiça (DEWEY, 2004, p. 96).

As possibilidades experienciais não estão predeterminadas. O universo ainda está se fazendo, num tornar-se marcado pela invencível contingência (DEWEY, 2004, p. 35; DEWEY, 2007, p. 236). Compõe-se de um "conjunto infinito de elementos que se relacionam de maneira a mais diversa possível. A multiplicidade e a variedade dessas relações o fazem essencialmente precário, instável, e o obriga a perpétua transformação" (TEIXEIRA, 1980, p. 113).

É nesse cenário, em que os homens não estão inscritos em nenhuma metahistória, que Dewey se ocupa, filosoficamente, da construção racional e criativa de nossas experiências.

Não se justifica que a filosofia habite apenas a região de seus próprios conceitos, "ao invés de auxiliar o homem a resolver problemas concretos, fornecendo-lhe hipóteses a serem usadas e testadas em projetos de reforma”. Como proposta pragmatista, a filosofia reconstruída se volta à experiência, concebendo o pensar comprometido com a práxis, com o que assume um caráter marcadamente contextualista (DEWEY, 2004, p. 70, 93 e 110).

Aposta, então, na incorporação, pela filosofia social, da disposição intelectual que acompanhou o desenvolvimento da ciência moderna. Não se trata, porém, de mera valorização das "verdades científicas". A difusão das qualidades da ciência, ressalta Dewey, não se reduz à "disseminação dos resultados da física, química, biologia e astronomia”. O fator científico integrado à reconstrução filosófica é, precipuamente, a qualidade da ciência moderna de uma atitude investigativa, metódica, experimentale falibilista (DEWEY, 1989, p. 111 e 117; DEWEY, 2004, p. v e 44), fundada "na observação e na experiência, na hipótese, na verificação e na revisão constante de suas conclusões" (TEIXEIRA, 1959, p. 01).

Ao trazer a perspectiva atitudinal da ciência, a reconstrução filosófica concebe-a intersubjetivamente, como pesquisa cooperativa da verdade e da moral. É essencial a perspectiva comunicativa da filosofia e, de modo geral, da construção do saber, necessariamente imersos num contexto linguístico. Não pode ser diferente.

Primeiro, porque, influenciado pela psicologia social de Mead, Dewey compreende a constituição do indivíduo como processo social: o ego emerge da comunicação, por meio da qual participa do outro e, assumindo 
a atitude do outro em relação a si mesmo, ingressa em sua própria experiência, como um objeto para si. Obtém, assim, a autoconsciência, em interação, através do outro (MEAD, 1992, p. 138, 171, 226 e 253). O solilóquio é "o resultado e o reflexo da conversação com os outros" e não o contrário (DEWEY, 1980, p. 31). Eis um traço marcante do pragmatismo norte-americano: a ruptura com o subjetivismo da filosofia da consciência, ressaltando, em oposição, a dimensão intersubjetiva e histórica da mente (BERNSTEIN, 1992, p. 814).

Segundo, porque a linguagem que possibilita a formação da individualidade é ela mesma o instrumento para a expansão e correção do saber comunicado. Nem imperfeições que pervertem o discurso em meio de dominação, retiram dele seu inigualável potencial de aprendizagem (DEWEY, 1980, p. 39 e 51; DEWEY, 2007, p. 236).

A razão individual é falível. Quando não compartilhadas, as ideias "são apenas solilóquio e solilóquio é apenas pensamento imperfeito e débil" (DEWEY, 1991, p. 218). Todo saber reivindica a permanente abertura ao teste e à crítica de suas pretensões de validade, no ambiente discursivo (BERNSTEIN, 1992, p. 814). E quanto melhor a qualidade dos participantes, em termos da disposição científica e comunicativa, com o maior número de participantes possível, maiores as chances de uma resposta razoável à questão debatida (HONNETH, 1998, p. $772)$.

A filosofia deweyana mantém, dessa forma, a aposta no projeto iluminista de emancipação, por meio da razão, do conhecimento, apesar de toda sua falibilidade, de seu uso imoral em proveito de poucos e das tantas barbáries que provocou no curso da modernidade. Porém, desprovida de bases seguras metafísicas para a afirmação solipsista da verdade e da moral, a razão, sem negar a si, emerge e se compromete com a práxis, a experiência em que aparece inevitavelmente ligada à interação comunicativa.

\section{A EXPERIÊNCIA, O PENSAR E O CRESCIMENTO}

Tais características do programa filosófico deweyano se consolidam nas formulações sobre a experiência, o pensare o crescimento cognitivo e moral do indivíduo.

I. A experiência constitui conceito base na filosofia reconstruída. Dewey fala de uma experiência ativa, definindo-a como a interação próxima e contínua entre o agir e ser submetido às mudanças, no ambiente, em consequência da ação (DEWEY, 2004, p. 49).

Destaca, no âmbito das experiências humanas, a atuação da razão, de modo experimental, planejador e criativo. A razão não paira sobre a experiência, como pretendia a metafísica. O conhecimento "não é algo separado e autossuficiente, mas está envolvido no processo pelo qual a vida é mantida e desenvolvida”. A razão é inteligência experimental, aplicada no enriquecimento da experiência da qual emerge (DEWEY, 2004, p. 54 e 55).

Dewey identifica dois princípios inseparáveis que determinam a configuração da experiência. Primeiro, o 
princípio da interação, de acordo com o qual "Uma experiência é sempre o que é por causa de uma transação acontecendo entre um indivíduo e o que, no momento, constitui seu ambiente", físico e social (DEWEY, 2010, p. 45). Segundo, o princípio da continuidade. Significa que "toda a experiência tanto toma algo das experiências passadas como modifica de algum modo a qualidade das experiências que virão". Afinal,

(...) toda a ação praticada ou sofrida em uma experiência modifica quem a pratica e quem a sofre, ao mesmo tempo em que essa modificação afeta, quer queiramos ou não, a qualidade das experiências subsequentes, pois, ao ser modificada pelas experiências anteriores, de algum modo, será outra pessoa que passará pelas novas experiências (DEWEY, 2010, p. 35 e 36).

Ao se combinarem os dois princípios, diferentes situações de interação sucedem umas às outras, levando-se algo, inevitavelmente, de uma experiência para outra. Da perspectiva do sujeito que experiencia, conforme "passa de uma situação para outra, seu mundo, seu ambiente, se expande ou se contrai" (DEWEY, 2010, p. 45). Nesse continuum que compõe o processo de vida, em relação com, as possibilidades de abordagem da realidade são delineadas; os hábitos de pensar, agir e conviver construídos; os horizontes de possibilidades de existência descortinados.

O modo como, historicamente, efetiva-se a experiência, num contexto de vida concreto - com suas tradições, instituições, valores e práticas sociais - vai sedimentando a maneira como o pensar e o agir operam. Com isso, sedimenta a forma como os sujeitos concebem o ambiente e atuam sobre ele, moldando e reconstruindo a própria experiência.

Só podemos experienciar o mundo sob a perspectiva do que somos no desenrolar de nosso processo vital. Quanto ao resultado disso, a direção para a qual caminham as experiências, o modo como se renova e se transforma seu conteúdo, estão diretamente relacionados à qualidade com que, em cada momento, são atualizadas e experienciadas (DEWEY, 2010, p. 38 e 46).

II. Nesse cenário, a atividade do pensar e, a partir da ideia formada, a interação, assumem lugar e sentido bastante precisos. São interpretados como hábitosformados na experiência.

O pensar, em seu melhor sentido, o reflexivo, racional, coadunado com a atitude cientifica, apresenta-se como um complexo processo de solução de dificuldades, conflitos e lacunas na experiência. Nas palavras de Mead, com quem Dewey compartilhou tal perspectiva psicológica, a mente humana, como "pensamento solucionador de problemas", é o "instrumento adquirido socialmente, por meio do qual indivíduo resolve os vários problemas de ajustamento ao ambiente, que surgem para confrontá-lo no curso da experiência”. É, por isso, o instrumento por meio do qual a reconstrução experiencial pode ser efetivada (MEAD, 1992, p. 308).

Tem origem, sempre, em alguma perplexidade, hesitação, dúvida. O pensar, definitivamente, "não é um caso de combustão espontânea; ele não ocorre sobre princípios gerais". Há sempre um problema específico que o evoca (DEWEY, 1997, p. 12). 
Dada a dificuldade, o próximo passo é a "pausa" no curso da ação, para inferir uma resposta. O pensar exige a aplicação da fórmula "pare e pense", para que possamos apreender o significado do problema, as circunstâncias em que se efetiva, suas conexões e possíveis consequências, e, então, selecionar uma dentre as possibilidades de solução que se abrem (MEAD, 1992; p. 99; DEWEY, 2010, p. 66).

Chega-se, assim, a uma ideia, hipótese teórica que funciona como plano de ação; ferramenta para a solução de lacunas da experiência; instrumento para a "ativa reorganização do ambiente dado, para a remoção de específicos problemas e perplexidades (DEWEY, 1997, p. 75; DEWEY, 2004, p. 90).

A ideia é concebida com base nos elementos presentes na experiência e no inventário cognitivo do sujeito, o "estoque" de conhecimentos e competências que, permanentemente reconstruído a partir de experiências anteriores, intermediam sua relação com o ambiente. Eis o material do pensamento (DEWEY, 2010, p. 70).

Sem experiências anteriores que, em alguma medida, aproximem o sujeito da solução do problema enfrentado, a "confusão permanece mera confusão. Não há nada a partir do que inferir a fim de esclarecê-la". A aptidão para uma resposta adequada ao problema, reorganizando o significado do universo experiencial, está diretamente vinculada à experiência nesse mesmo universo. Em qualquer hipótese, porém, independentemente da maturidade do sujeito, a operação do pensar, como caminhar do presente ao que é ausente, será sempre um salto aventureiro, arriscado. É falível, inevitavelmente (DEWEY, 1997, p. 12, 19 e 75).

O processo não para na ideia formada: "a elaboração pelo raciocínio pode fazer a ideia sugerida muito rica e plausível, mas ela não determina sua validade", isto é, sua verdade e, no âmbito moral, seu bem. Estes devem ser aferidos, tentativa e necessariamente, na prática, em sua aptidão para resolver a lacuna na experiência. Para ser completo, o pensar deve terminar onde tudo começou, no domínio da práxis, da ação interrompida por um problema. Evidencia-se, assim, o movimento duplo do processo reflexivo, partindo do problema, na experiência, em direção às sugestões de significado e de resposta; e, depois, partindo destas, de volta à situação problemática, experimentando as ideias cogitadas (DEWEY, 1997, p. 72,79 e 96).

Somente no plano prático pode ser conferida a pretensão de validade da ideia, marcadamente instrumental: "Como é o caso de qualquer ferramenta, seu valor reside não em si mesma, mas na sua capacidade de funcionar, mostrada nas consequências de seu uso". Se tem sucesso nessa empreitada, eliminando a incerteza, a confusão, o conflito, é válida; porém, se, colocada em ação, falha, é inválida (DEWEY,2004, p. 83 e 90).

Dessa forma, o pensar reflexivo pode se atualizar como operação emancipadora. Possibilita ao ser humano a solução dos conflitos vivenciados cotidianamente, enriquecendo o sentido de sua experiência, sem ser empurrado para a ação irrefletida, pela força do hábito, de impulsos libidinais e do acaso (DEWEY, 1997, p. 67). 
III. No continuum experiencial, a partir do qual o pensar, o agir e o conviver se formam e se tornam habituais, tem lugar o crescimento cognitivo e moral do sujeito. De acordo com a perspectiva social de constituição do indivíduo, o crescimento, em Dewey, aparece como processo em que, na experiência comunicativa, o sujeito torna-se - pelo menos, pode se tornar - cada vez mais social, mais racionale mais moral(DEWEY, 2008, p. 13). Distingue, nele, três níveis de conduta, na direção da autonomia.

O primeiro nível é o pré-moral ou pré-convencional, em que a conduta é motivada, basicamente, por impulsos e necessidades biológicas e físicas: "Nós começamos a vida sob a influência de apetites e impulsos e da resposta direta aos impulsos imediatos de calor e frio, conforto e dor, luz, barulho, etc.”. A partir da daí, em função da dependência absoluta do bebê, o eu e o mundo passam a ser constituídos mediados por outras pessoas. Elas "determinam quais experiências a criança deve ter; eles instruem-na quanto ao significado do que ela faz e sofre". Desse modo, o indivíduo, progressivamente, ingressa no universo da linguagem e, a partir dele, como um si mesmo, no mundo (DEWEY, 2004, p. 53; DEWEY, 2008, p. 12 e 169).

As perspectivas e as expectativas do grupo vão sendo infundidas na criança, por meio de estímulos, determinações, aprovações e reprovações. Constituem os critérios de que dispõe para a percepção e interpretação das próprias experiências:

As coisas vêm a ela vestidas em linguagem, não em sua nudez física, e esse traje de comunicação faz dela uma participante nas crenças deles (os membros do grupo social) sobre ela. Essas crenças, vindo a ela, como tantos fatos, formam sua mente; fornecem os centros sobre os quais suas próprias explorações e percepções pessoais são ordenadas. Aqui temos "categorias" de conexão e unificação tão importantes como aquelas de Kant, mas empíricas, não mitológicas (DEWEY, 2004, p. 53).

Nesse processo de internalização das atitudes do outros, a personalidade moral emerge, essencialmente, na expressão de Mead, como me, isto é, o aspecto convencional do indivíduo, constituído pelo "conjunto organizado das atitudes dos outros que o sujeito assume". A ele, a pessoa em formação reage, na expressão de $s i$ mesmo, como eu (MEAD, 1992, p. 175 e 200).

Chega-se, dessa maneira, ao segundo nível de conduta, o heterônomo ou convencional. Aqui, o indivíduo está inserido no universo cultural do grupo, compartilhando suas experiências, valores e hábitos. Participa do pano de fundo de entendimento mútuo, inconscientemente assimilado, em que ocorre a interação. Porém, circunscrito o pensamento a esse mobiliário mental captado acriticamente, "não sabemos como", o indivíduo ainda "aceita com relativamente pequena reflexão crítica os padrões e formas de seu grupo, tal como incorporados nas tradições e costumes" (DEWEY, 1997, p. 04 e 214; DEWEY, 2008, p. 12). Na linha da filosofia kantiana, sujeita-se a convenções e normas heterônomas, alheias à própria razão, pois dadas de fora (KANT, 2008, p. 79).

A heteronomia é vencida, como em Kant, no terceiro nível de conduta, a autonomia. Porém, diferentemente de sua filosofia da consciência, é intersubjetivamente construída e praticada. A autonomia, na 
abordagem deweyana, refere-se ao processo construtivo de crescimento do sujeito histórico, concreto, em sua experiência social.

Valendo-se das aprendizagens e ferramentas proporcionadas pela linguagem e pelo universo cultural em que ingressara e do qual, agora, participa, o sujeito pode, finalmente, distanciar-se das instituições e práticas sociais. Superando a personalidade convencional, faz emergir a colisão entre o eu e os outros, no que se refere à verdadee ao valor da experiência (DEWEY, 2007, p. 236; DEWEY, 2008, p. 14).

Com a reorganização de suas experiências e de seu inventário cognitivo, o indivíduo, no estágio da autonomia, habilita-se ao pensar reflexivo e, por meio dele, "pensa e julga por si, considera se o propósito é bom ou certo, decide e escolhe, não aceitando os padrões de seu grupo sem reflexão". Pode atuar inteligentemente na direção de sua experiência e na solução dos problemas em seu curso. Diante de conflitos, consegue avaliá-los, conferindo-lhes sentido e participando do discurso, em busca de soluções moralmente boas (DEWEY, 2008, p. 12).

A autonomia moral-cognitiva implica, assim, fundamentalmente, liberdade de inteligência: o "poder mental de exercício independente, emancipado dos cordões condutores dos outros" para a significação, o julgamento, a direção e a reconstrução da experiência comunicativa, na qual o sujeito se constituiu (DEWEY, 1997, p. 67; DEWEY, 2010, p. 63 e 66). Trata-se de uma liberdade que, superando o sentido individualista negativo, remete à atualização das potencialidades individuais na comunicação. É liberdade comunicativa. Tem "lugar apenas em rica e múltipla associação com os outros", fazendo-se como "poder de ser um eu individualizado fazendo uma contribuição peculiar e usufruindo de seu modo, os frutos da associação". Enfim, como destaca Dewey, nenhum indivíduo "jamais foi emancipado meramente sendo deixado sozinho. A remoção das limitações físicas é apenas uma condição negativa; liberdade positiva não é um estado, mas uma ação". Realizando-se, ativamente, em interação, aproveitando o potencial de aprendizagem da comunicação, na direção do crescimento, é inseparável da noção de responsabilidade. Liberdade e responsabilidade são compreendidas nesse sentido moral, "conectado com possibilidade de crescimento, aprendizado e modificação da qualidade" (DEWEY, 1991, p. 150 e 168; DEWEY, 2008, p. 305).

Assim compreendido, o crescimento não tem um termo final preestabelecido. Ele é o fim. Não existe um padrão fixo de ego a ser atualizado. Compreendido em termos dinâmicos, "Cada eu vivo age e é afetado, em contrapartida, pelo que faz. Toda ação voluntária é um refazer do eu, visto que cria novos desejos, instiga novos modos de comportamento, traz à luz novas condições que instituem novos objetivos" (DEWEY, 2008, p. 306).

Nesse processo, a reconstrução subjetiva de significados, mediada pela experiência social, caminha junto com a reconstrução objetiva, do ambiente físico e social. As maiores habilidades, conhecimentos e experiências possibilitam a compreensão mais profunda e a ação mais inteligente sobre o ambiente, reconstruindo-o 
positivamente. Traz, concomitante e incessantemente, novas questões, mais profundas, a serem solucionadas por sujeitos mais aptos a lidar com elas. Possibilita o crescimento em geral, promotor de outros crescimentos, em outras direções, de todo o grupo social (DEWEY, 2010, p.37, 48 e 51).

Tudo isso, porém, apenas pode ser assim. Não se trata de um processo necessário. O continuum experiencial não está predeterminado por nenhuma metanarrativa histórica

IV. O pensar, agir e conviver reflexivos - assim como sua deturpação irrefletida - são habilidades construídas e reconstruídas, a partir das experiências de vida. Tornam-se habituais dentro de certas linhas e perspectivas, traçadas sob a influência das tradições do grupo social. Determinam, então, a forma como o sujeito atuará sobre seu ambiente (DEWEY, 1991, p. 160).

Os hábitos de pensar, agir e conviver e a experiência combinam-se, por conseguinte, numa correlação de influência recíproca. Aparecem como causa e efeito um do outro, no processo reconstrutivo objetivo e subjetivo que não está, de nenhuma forma, predeterminado.

Educação e democracia não podem ser concebidas nem praticadas sem a percepção clara dessa correlação. Devem, para Dewey, ser compreendidas nesse movimento contínuo e gradual de constituição da individualidade e de enriquecimento das experiências sociais.

Nesse movimento, a força do hábito e a força das condições objetivas, dele perpetuadoras, ambas moldadas no curso da história, não podem ser subestimadas. Asseguram duplamente a continuidade e explicam porque "quanto mais as coisas mudaram, mais elas permaneceram as mesmas" (DEWEY, 1991, p. 161).

$\mathrm{O}$ que temos em mãos para desenvolver novas ideias são as antigas ferramentas cognitivas. O que permite construir novas experiências no futuro são as experiências passadas. Daí porque as mudanças profundas não serem possíveis de pronto, recomeçando-se do zero, a partir de uma tabula rasa que possibilitasse a criação de uma nova ordem das coisas e mentes (DEWEY, 1991, p. 162; DEWEY, 2004, p. 43 e 54).

São evidentes as dificuldades inerentes ao desfazimento dos velhos hábitos e à superação do me convencional. Experiências educativas e sociais, no sentido da consolidação e aprofundamento da democracia, indicam uma caminhada gradual e progressiva. E isso no âmbito do processo da interação entre os sujeitos, em que todos se transformam e modificam um ao outro, num continuum experiencial.

\section{A PROPOSTA DEWEYANA DE DEMOCRACIA}

$\mathrm{Na}$ linha dos conceitos apresentados, a filosofia social deweyana apreende a democracia como processo comunicativo de solução compartilhada de conflitos de coordenação social, assim identificados pelos membros da comunidade, reunidos num público, com o amparo de uma estrutura governamental e, a ela relacionada, de mecanismos jurídico-institucionais para participação política. Corresponde a uma experiência social participativa, 
comunicativa, racional e moral-cognitivsta de autodeterminação, de autonomia.

O significado e o valor moral da organização democrática vinculam-se à ciência moderna, em sua qualidade de um hábito da mente reflexivo, investigativo, metódico, experimental, falibilista. E se atualiza na comunicação, como processo de busca cooperativa da verdade e do justo. Efetiva-se, nesse sentido, na sua aptidão de contribuir para melhores experiências sociais, possibilitando o crescimento contínuo dos membros da sociedade. Aliando o método científico e o democrático, no discurso, a democracia é a ambiência social em que pode se efetivar o projeto iluminista de emancipação (DEWEY, 1989, p. 81; DEWEY, 2004, p. 107; HONNETH, 1998, p. 772 e 773$)$.

Enriquece-se, destarte, de sentidos a ideia de democracia (e de Estado democrático de direito). Envolve, sem que possa, porém, ser expressa apenas em termos de procedimentos e mecanismos políticos-participativos, inscritos no ordenamento jurídico (eleições periódicas, direito ao voto, regra da maioria, etc.). A vivência da democracia e sua configuração jurídico-estatal se constroem e se reconstroem na referência fundamental à experiência comunitária que lhes antecede e sustenta (DEWEY, 1989, p. 97 e 101; DEWEY, 1991, p. 143 e 148).

I. O delineamento completo desse modelo vincula-se ao conceito de público, em torno do qual Dewey constrói sua teoria do Estado.

Explica o autor, o público - e a linha contextual, processuale experimentalmente traçada que o distingue do que é privado - remete, em primeiro lugar, à existência de consequências da interação humana, que se projetam de modo importante e invasivo, para além das pessoas diretamente envolvidas. Remete, desse modo, à existência de conflitos de coordenação social, no âmbito de uma dada comunidade. Ao mesmo tempo, decorre da percepção, pelos afetados, desses efeitos significantes e invasivos, de forma a considerar necessário o controle, pela inibição ou pela promoção. Personifica-se, então, num conjunto de pessoas com o interesse comum em controlar tais consequências e os problemas delas decorrentes, e que formam um público (DEWEY, 1991, p. 12, 13, 15 e126).

Evidentemente, diante da complexidade das relações humanas, da contingência dos problemas que podem envolver e da variedade de perspectivas pelas quais podem ser percebidas, não há que se falar num único e homogêneo público, compondo organicamente a sociedade, com idênticos interesses e valores (DEWEY, 1991, p. 65 e 137).

É num contexto complexo e pluralista que a dimensão do público se desenvolve como um meio discursivo de articulação de demandas e de solução de problemas. Nele, os membros de uma comunidade identificam e debatem os conflitos de coordenação social, formulam opiniões, organizam-se, reconhecem pretensões comuns, atuam em vista de sua solução. E se valem, instrumentalmente, de um aparelho políticogovernamental, dela demandando regulação e mediação, quando necessário, diante da forma como afetados pelas 
consequências invasivas da ação social (DEWEY, 1991, p. 35 e 39; HONNETH, 1998, p. 774).

II. O Estado é formado, nesse cenário, pela combinação do público com a estrutura juridicamente institucionalizada de governo, que do público emerge, como instrumento para sua regulação, mediação e realização de pretensões. Eis a definição deweyana de Estado: a organização do público por meio de um aparelho político para a proteção de interesses compartilhados (DEWEY, 1991, p. 33 e 35). Na mediação desses elementos, aparecem os códigos de direito.

A interação social, suas consequências e problemas trouxeram o público à existência. Ele, então, organizase como um Estado somando uma estrutura governamental: "Um público articulado e operando através de representantes oficiais é um estado; não há estado sem um governo, mas também não há nada sem o público” (DEWEY, 1991, p. 67).

Assim configurado, a qualidade de um Estado em particular é dada pelo "grau de organização do público" e pelo "grau em que seus representantes são constituídos de modo a efetivar sua função de cuidar dos interesses públicos". Trata-se de qualidade que, para o autor, pode ser atualizada experimentalmente, de modo mais inteligente e moral, na democracia. Pois está convicto de que a organização democrática, com "a consulta mútua e as convicções alcançadas pela persuasão", proporcionam uma "melhor qualidade de experiências humanas, consideravelmente mais acessíveis e proveitosas, do que as formas não democráticas e antidemocráticas de vida social" (DEWEY, 1991, p. 33; DEWEY, 2010, p. 34 e 35).

III. O Estado democrático de direito passa, portanto, sem dúvida, pela dimensão institucional governamental. A partir dela, Dewey engendra o sentido político da democracia, como "um modo de governo, uma prática especifica de selecionar agentes públicos e de regular sua conduta como pública", referido a instituições como sufrágio universal, eleições periódicas e regra da maioria (DEWEY, 1991, p. 82 e 144).

Tudo isso, porém, de acordo com o significado instrumental conferido ao governo: um medium por meio da qual o público exerce a soberania popular e pode, com o amparo de representantes eleitos, regular a experiência social e resolver seus conflitos. Na filosofia política deweyana, "o governo existe para servir sua comunidade" (DEWEY, 1991, p. 146).

Ainda que fundamental, essa dimensão institucional não faz, por si só, a democracia. A experiência democrática não se reduz a isso, absolutamente. Aliás, para o autor, o elemento mais significativo da fase política da democracia e, nela, da "contagem de cabeças", é o fato de que ela compele, necessariamente, aos recursos racionais prévios do "debate, consulta e persuasão". A regra de maioria “nunca é meramente regra da maioria”. Pois conduz, com imenso potencial educativo, o envolvimento da população. Força a troca de ideias, a reflexão conjunta sobre problemas comuns (DEWEY, 1991, p. 146, 206 e 207). 
Prevalece, enfim, a atenção ao momento comunitário precedente. A democracia expressa, também e fundamentalmente, atitudes, uma forma de conduta de vida dos atores sociais, em sua experiência comunitária (DEWEY, 1989, p.97 e 101).

IV. Quanto à comunidade, da qual o público emerge, Dewey a apreende para além da simples soma de sujeitos e ações individualistas, orientados à satisfação de fins egoístas. Identifica-a como experiência comunicativa e cooperativa. É impregnada de conteúdo moral, no sentido de que é "emocionalmente, intelectualmente e conscientemente sustentada", na direção de melhores experiências sociais (DEWEY, 1991, p. 151).

Remete a um universo de linguagem, em que, na comunicação, os membros do grupo são formados numa tradição cultural e, nela inseridos, participam cooperativamente das interações, contribuindo com a organização social, na medida de suas aptidões e possibilidades. A linguagem induz uma perspectiva existencial participante, na qual o sujeito, em sua particularidade, abre-se ao outro como parceiro de comunicação que compartilha o sentido do que foi falado (DEWEY, 1980, p. 36).

Sob esse enfoque moral-comunicativo, a experiência comunitária, da perspectiva do indivíduo, consiste em ter uma participação responsável nas atividades e valores do grupo, de acordo com suas capacidades e necessidades. Do ponto de vista do grupo, "exige atualização das potencialidades dos membros do grupo em harmonia com interesses e bens que são comuns" (DEWEY, 1991, p. 147).

Nesse sentido, como ressalta Honneth, a vida social "pré-política" deweyana e seu valor moral ancoramse na experiência da justa divisão social do trabalho. Dela provem a consciência da cooperação, para a realização de fins comuns: "Somente uma forma de divisão do trabalho que conceda a cada membro da sociedade, de acordo com as habilidades e talentos autonomamente descobertos, uma justa chance de assumir ocupações socialmente desejáveis permite que a consciência da cooperação surja" (HONNETH, 1998, p. 777).

A vida democrática aparece, dessa forma, como decorrência da experiência comunitária de participação e cooperação, por meio de uma contribuição individual, única, nas tarefas do grupo (HONNETH, 1998, p. 776 e 780).

Nesse processo, o "nós" emerge e se constitui tão inevitavelmente quanto o "eu"; sem que o indivíduo seja colocado em oposição ou anulado pelo social. Afinal, não se trata de um "indivíduo fixo, em isolamento e estabelecido por si mesmo", mas que se forma na interação, compartilhando valores, interesses e desenvolvendo um papel social (DEWEY, 1991, p. 151).

V. Aos laços comunitários, somam-se, ainda, na ambiência democrática, dois fatores indissociáveis, em vista da consolidação de seu valor racional, cognitivo e moral, na solução de conflitos de coordenação social.

i. Primeiro, o hábito reflexivo e comunicativo de pensar, agir e conviver, marcado pela atitude científica, por 
parte dos cidadãos. Dewey não está propondo, com isso, um governo tecnocrata, desconectado do público, de suas necessidades e do interesse comum. Tampouco está sugerindo que todos os cidadãos sejam cientistas. O que propõe é a assimilação, na forma de vida dos atores sociais, daquela disposição investigativa, experimental, metodológica, falibilista, que marca a atitude científica. Pois é esse hábito que possibilita a superação dos equívocos alimentados por tradições irrefletidamente assimiladas, dos preconceitos e medos pessoais e de classe e, ainda, dos enganos decorrentes da propaganda e da difusão de informações em favor de grupos de interesses. Aparece como a "única garantia da possibilidade de uma opinião pública inteligente o suficiente para equacionar os problemas sociais presentes" (DEWEY, 1989, p. 114; DEWEY, 1991, p. 206).

Atualizada no discurso, permite a incorporação, na prática social, da perspectiva metodológica pragmatista de pesquisa cooperativa da verdade. Promove, dessa forma, uma concepção ativa da cidadania, em que o sujeito, fazendo uso de sua liberdade comunicativa, envolve-se no debate público, colaborando com a afirmação do público e participando da investigação, do debate e da experimentação de soluções aos conflitos sociais e de novas possibilidades experienciais.

A necessária atuação do cientista e do técnico, aqui, não tem um sentido tecnocrático. Realiza-se, fundamentalmente, no papel de cidadão que participa do público, trazendo ao debate contribuições técnicocientíficas e elevando, então, "o nível em que a inteligência de todos opera" (DEWEY, 1991, p. 210).

ii. Segundo, o ambiente público de livre comunicação, que possibilite o compartilhamento e a correção do saber produzido e, valendo-se dele, a melhoria permanente das experiências comunitárias. A afirmação do público, a atualização do discurso e, a partir deles, a coordenação da ação social não prescindem de uma ambiência em que prevaleça a liberdade de expressão, de comunicação e de pesquisa; a tolerância em relação a visões diferentes; a distribuição dos resultados da pesquisa e do debate. Todos eles, fatores envolvidos "no método democrático tanto quanto no método científico". (DEWEY, 1989, p. 81; DEWEY, 1991, p. 184).

Desse modo, a participação dos cidadãos, sem constrangimentos e com iguais direitos, aumenta as chances de respostas adequadas às demandas e conflitos, experimentados pelo grupo social. $\mathrm{Na}$ aliança bemsucedida com os métodos científicos, as práticas democráticas aparecem como "condição para o aumento da racionalidade das soluções dos problemas sociais" (HONNETH, 1998, p. 772, 773 e 775). Indicam a maior e melhor participação de pessoas, no enfrentamento das questões comuns, num compartilhar por meio do qual "os significados são ampliados, aprofundados e consolidados no sentido da participação" (DEWEY, 1980, p. 51).

Lidos na perspectiva jurídica, tais fatores remetem ao reconhecimento dos direitos humanos fundamentais, em todas as suas dimensões, no âmbito do Estado democrático de direito. Afinal, o cenário de 
participação racional e competente, em igualdade de condições, nos processos de solução compartilhada dos problemas comuns, somente se efetiva mediante o exercício dos direitos individuais de liberdade, dos direitos políticos de participação e dos direitos sociais, dentre os quais se destaca, aqui, a educação.

$\mathrm{Na}$ medida, então, em que se concretizam, promovendo o enriquecimento das experiências sociais, renovam e expandem, numa espiral positiva e contínua, os conteúdos dos direitos humanos e da democracia.

Em J.Habermas - autor da Escola de Frankfurt que reconhece a influência do pensamento deweyano na construção de seu modelo de democracia (HABERMAS, 2011, p. 27) - isso aparece na formulação de que a práxis democrática da autonomia, da autolegislação realiza-se e adquire sentido no âmbito do próprio sistema jurídico, o qual garante as condições para sua própria construção e reconstrução discursiva (HABERMAS, 2012, p. 163)

VI. Sem dúvida, a experiência ampliada da democracia apresenta-se como um processo gradual, complexo, conflituoso e contingencial.

Se os elementos da experiência democrática pressupõem, favorecem e fortalecem uns aos outros, num continuum experiencial, isso não é, de nenhuma forma, necessário. Exigem, para sua efetivação, uma atitude que não é inata ao ser humano. $\mathrm{O}$ pensar e o agir democraticamente não são dádivas que se atualizam espontaneamente (como também não é o inverso autoritário). São hábitos formados experiencialmente e consolidados em espaços e instituições sociais, dentro da própria experiência democrática (DEWEY, 1989, p. 97).

A democracia não prescinde de processos de aprendizagem. É a experiência contínua e renovada da democracia, com todas as suas imperfeições, que proporciona aos cidadãos a aprendizagem de suas práticas. Dela decorre o fortalecimento do público e dos espaços comunicativos, com o "aperfeiçoamento dos métodos e das condições de debate, discussão e persuasão", bem como o funcionamento do aparelho governamental, de forma comprometida com as demandas sociais, sob a vigência do Estado democrático de direito. Eis o sentido em que, para Dewey, deve ser apreendida a ideia de que "a cura para os males da democracia é mais democracia" (DEWEY, 1991, p. 82, 144 e 208).

\section{A PROPOSTA DEWEYANA DE EDUCAÇÃO}

No âmbito da experiência da democracia e em vista de seu fortalecimento contínuo, tem lugar a proposta de educação progressiva. Dewey a enraíza na ideia de experiência, vista como "os meios e as metas da educação". Define, nesse sentido, seu pensamento pedagógico - parafraseando Lincoln ao falar da relação entre o governo democrático e o povo - como "uma filosofia da educação de, por e para a experiência" (DEWEY, 2010, p. 30 e 93$)$.

Não se trata de qualquer experiência, mas sim daquela com a qualidade para promover sempre mais 
educação, a experiência educativa. O reconhecimento de que a vida, a experiência e a aprendizagem não se separam (TEIXEIRA, 1980, p. 115), "não significa que todas as experiências são verdadeiramente ou igualmente educativas (...) Algumas experiências são deseducativas" (DEWEY, 2010, p. 26 e 27).

I. É no contexto norte-americano da primeira metade do século XX, que Dewey apresenta sua concepção pedagógica progressiva, mais humana e democrática. Visa à superação do que denomina o método tradicional: perspectiva que, a seu ver, não proporciona experiências educativas, colocando-se na contramão do projeto democrático. Apesar disso, completa o autor, conspira a seu favor "a tendência de pais e escolas autoritárias em demandar rápidas e tangíveis evidências de progresso", ainda que ao custo da "dependência de pura memorização e rotina mecânica" (DEWEY, 1997, p. 54 e 61).

A perspectiva tradicional reduz o processo educativo à transmissão unilateral e impositiva de informações, "de cima para baixo e de fora para dentro". Corresponde ao ensino do passado, um "produto acabado" de "sociedades que consideram que o futuro será exatamente como o passado, e que passa a ser usado como substância educacional em uma sociedade em que a mudança é uma regra e não uma exceção" (DEWEY, 2010, p. 21).

Partindo de um conteúdo que se encontra fora da experiência de vida dos educandos e ao qual é atribuído um valor educacional em si, edifica-se sobre o equívoco conceitual de que, ao transmiti-lo, os educandos estarão preparados para o futuro.

A pedagogia tradicional ignora as particularidades do estudante, suas experiências e as perplexidades por ele vivenciadas, negligenciando, com isso, do exercício do pensar reflexivo. Apela a um despropositado pensar de modo genérico, sem referência à existência, na experiência do aluno, de alguma dificuldade que o perturbe. Atualizando-se na distância entre as experiências, os problemas e os recursos cognitivos da criança, de um lado, e, de outro, os conteúdos ensinados e os resultados esperados, tem que ser impositiva. Não há alternativa (DEWEY, 1997, p. 12; DEWEY, 2004, p. 106; DEWEY, 2010, p. 21, 47 e 79).

O ensino se consolida como uma "dieta de matérias pré-digeridas", em que cabe ao aluno tomar as doses prescritas (DEWEY, 2010, p. 47 e 48), crítica que aparece, mais tarde, em Paulo Freire - em quem a obra deweyana ecoou, sobretudo por meio dos trabalhos de Anísio Teixeira (GHIRALDELLI JUNIOR, 2003, p. 118; MURARO, 2013, p. 813, e 824) -, sob a denominação "educação bancária": a educação reduzida em "ato de depositar, de transferir, de transmitir valores e conhecimentos” (FREIRE, 201 1, p. 82).

$\mathrm{Na}$ estrutura tradicional, "a atitude dos alunos deve ser, no geral, de docilidade, receptividade e obediência". O educando habitua-se a aceitar, memorizar e repetir as ideias alheias, sem investigação pessoal, nem teste de seu valor. Utiliza o pensamento "para descobrir o que os outros acreditam e, então, para. As ideias dos outros, como encarnadas na linguagem, tornam-se o substituto para as próprias ideias". (De)forma-se para a "vida 
parasita em experiências de segunda mão" (DEWEY, 1997, p. 177; DEWEY, 2010, p. 65).

Nega-se ao educando, dessa maneira, a oportunidade de, progressivamente, conferir sentidos, questionar e recriar sua experiência, ampliando suas possibilidades existenciais e participando da experiência social, na medida de sua capacidade cognitiva, em permanente reorganização. Em oposição ao diálogo, reduz a linguagem ao aspecto de imposição e unilateralidade. Despreza, em favor da resposta predita, a pesquisa dialógica para a construção cooperativa dos significados da experiência.

A pedagogia tradicional efetiva-se de forma antidemocrática do princípio ao fim. Renunciando à práxis democrática, não habilita nem habitua à democracia. Ensinar o que é democracia, definindo o termo, não pode ir além do plano abstrato de uma teoria não praticada, de um sentido não vivido.

II. A oposição ao modelo tradicional não conduz Dewey a uma formulação antitética, no outro extremo, numa linha não-diretivista, conforme acusação tão disparada contra ele.

Sua filosofia educacional enraíza-se, como antecipado, na experiência educativa. E por educação, Dewey entende o processo contínuo de crescimento intelectual e moral. Um processo comunicativo de constante reorganização da experiência, por meio do qual o sujeito, adquirindo experiências e reconstruindo seus recursos cognitivos, amplia e aprofunda o significado de sua experiência e desenvolve a habilidade e o hábito de um sempre melhor controle e direção do curso das experiências subsequentes (DEWEY, 1916, p. 63, 89 e 90).

De acordo com sua máxima moral do crescimento como fim, o crescimento contínuo do educando, com cada vez mais autonomia moral-cognitiva, é o fator que define a qualidade educativa da experiência. É educativa a experiência que habilita e dispõe o educando a continuar sua educação, continuar crescendo. E isso, valendo-se do potencial de aprendizagem do discurso.

Para tanto, a experiência educativa deweyana envolve os seguintes princípios:

i. Em primeiro lugar, o desenvolvimento do pensar, agire conviver reflexivos, com a atitude cientifica.

Como hábito formado na experiência, o pensar - e o correlato agir e interagir -, no seu melhor sentido, não surge naturalmente, sendo, ademais, não raro, prejudicado pelo ambiente social, promotor de "hábitos equivocados de pensar", na assimilação acrítica da tradição cultural (DEWEY, 1997, p. 25 e 28).

A educação progressiva, opondo-se à redução do processo educativo ao depósito de informações na mente do educando, centra sua atenção e se organiza para a formação de "bons hábitos de pensar" (DEWEY, 1916, p. 192).

Considerando, então, que o passo inicial da operação do pensamento consiste num genuíno problema que emerge da experiência do sujeito, a relação estabelecida entre educação e o exercício do pensar remete, desde logo, em Dewey, a dois princípios básicos de organização da experiência educativa.

Primeiro, a derivação dos conteúdos educacionais das experiências comuns de vida. A educação deve 
estar ligada às experiências de vida do aluno. Deve partir delas, de modo que "Tudo o que possa ser considerado como matéria de estudo, seja aritmética, história, geografia ou qualquer uma das ciências naturais, deve derivar de materiais que, originalmente, pertençam ao escopo da experiência comum cotidiana” (DEWEY, 2010, p. 75).

Segundo, a educação baseada na solução de problemas, extraídos da experiência, a serem vencidos por meio do exercício do pensamento. São absolutamente infrutíferos, para o autor, os "apelos genéricos à criança (ou ao adulto) para pensar", sem a consideração de alguma dificuldade que o incomode. O pensar começa com um problema que deve ser seu, surgindo de sua experiência e lhe causando perplexidade(DEWEY, 1997, p. 12).

Somente assim, a experiência educativa pode capacitar o educando ao processo complexo do pensar. Permite-lhe a apreensão sempre mais adequada de sua experiência; a inferência de respostas, cada vez mais profundas ao problema colocado; o raciocínio amparado em conclusões fundamentadas; e, finalmente, fechando o percurso do pensamento, a aplicação das respostas, testando-as, para "fazer seu sentido claro e descobrir por si mesmo sua validade" (DEWEY, 1916, p. 192; DEWEY, 1997, p. 27 e 28).

Promove-se, assim, a autonomia cognitiva e moral, a liberdade da mente "capaz de se orientar independentemente, sem tutela externa". A disciplina da mente, permitindo o exercício inteligente do pensar, é vista como fator libertador. Positiva e construtivamente concebida, é sinônimo de liberdade de inteligência, a liberdade emancipadora do agir irrefletido, o rotineiro, preso à tradição, e o impulsivo, determinado por forças libidinais (DEWEY, 1997, p. 63 e 64; DEWEY, 2010, p. 66 e 67).

ii. A experiência educativa corresponde, por isso, à "experiência inteligente em que participa o pensamento". De acordo com a maturidade e com os recursos cognitivos do educando, em permanente reconstrução, capacita-o à solução de problemas na experiência, apreendida de modo sempre mais complexo. Concomitantemente, o sujeito se habilita a nela atuar, reconstruindo-a objetivamente, de modo mais racional, mais adequado aos propósitos estabelecidos (TEIXEIRA, 1980, p. 116; DEWEY, 2010, p.93).

Segue-se, desse modo, uma trajetória moral-cognitivista que vai da heteronomia à autonomia: um percurso gradual e contínuo de crescimento, de par com o alargamento universo experiencial do sujeito.

Para a efetivação desse percurso intelectual e moral, Dewey afirma mais um princípio da experiência educativa: o desenvolvimento progressivo dos conteúdos educacionais de acordo com a maturidade do aluno. Propõe, com ele, a reorganização e aprofundamento dos conteúdos na medida em que vai se adensando o olhar do educando (DEWEY, 2010, p. 76).

Partindo das experiências de vida dos alunos, apreendidas conforme seu nível de maturidade, e baseando-se em problemas nelas identificados - solucionados por meio do exercício do pensar-, o processo educacional amplia e enriquece o universo experiencial. Apresenta novos e mais complexos problemas, 
enfrentados por sujeitos sempre mais aptos. Num continuum experiencial positivo:

O conhecimento adquirido em cada experiência entra em conexão com novos objetos e acontecimentos que requerem novas capacidades, ao mesmo tempo em que o exercício dessas capacidades refina e amplia o conteúdo dessas experiências. As dimensões vitais de espaço e tempo são expandidas. O ambiente, ou seja, o mundo da experiência se torna constantemente maior e, supostamente, mais, denso (DEWEY, 2010, p. 76).

Dessa maneira, auxiliando o educando a extrair, de sua experiência presente, "tudo o que nela há no momento em que a vivencia”, a educação o prepara para ser capaz de fazer o mesmo no futuro. Conclui Dewey: "Sempre vivemos o tempo em que estamos e não algum outro tempo, e só extraindo de cada tempo o sentido completo de cada experiência presente que estaremos preparados para fazer o mesmo no futuro. Essa é a única preparação que realmente conta ao longo da vida” (DEWEY, 2010, p. 48, 50 e 51).

O sujeito constrói e qualifica o olhar sobre o mundo em construção, habilitando-se a responder de modo mais coerente aos problemas, sempre mais complexos, que se lhe apresentam (DEWEY, 2004, p. 77 e 81).

iii. A liberdade de inteligência e a autonomia moral-cognitivista são apreendidas, na teoria deweyana, intersubjetivamente. Perfazem-se na comunicação. Para chegar aí, a educação tem de se consolidar como um processo comunicativo, construindo-se na linguagem, a partir da qual a individualidade é formada e dentro da qual o saber e a experiência atingem seu melhor sentido. Emerge, aqui, outro princípio da experiência educativa: a interação dialógica.

Todo e qualquer processo formativo passa, inevitavelmente, pela comunicação. Porque o solilóquio da mente é reflexo da conversação com os outros, os hábitos de pensar são moldados, em grande medida, pela forma como se efetivou a experiência comunicativa.

A comunicação pode se deturpar em imposição e unilateralidade, favorecendo a conformação de um pensar passivo e dogmático. Mas pode, também, fazer-se dialogicamente, na interação que rompe a unilateralidade e em que o educando, "é libertado de seu isolamento imediato e participa da comunhão de significados" (DEWEY, 1980, p. 51).

Desse modo, enriquecida no sentido do diálogo, a experiência educativa implica a inclusão do educando, trazendo o contexto histórico-social em que se insere, suas experiências e suas perplexidades, para o processo formativo.

Refletindo, então, a interação dialógica, o educando pode desenvolver o hábito de pensar como prática cooperativa, inclusiva do outro. Superando os equívocos da razão solipsista e os particularismos de seu universo linguístico, a pessoa dispõe-se ao compartilhamento, à expansão e à correção do saber, no discurso, beneficiandose dos potenciais de aprendizagem que the são inerentes.

Ao formar para um pensar que remete à construção compartilhada de respostas aos problemas 
experienciados, a educação progressiva deweyana habilita o sujeito a apreender e vivenciar a experiência em relação com: interação que, ampliada à convivência social e ao discurso para o enfrentamento de conflitos percebidos como públicos, define a democracia.

iv. A constatação de que crescimento e, com ele, os hábitos reflexivos, comunicativos e democráticos, não surgem naturalmente, de modo espontâneo, leva a um último princípio da experiência educativa deweyana: a pedagogia diretiva.

O percurso cognitivo e moral da heteronomia à autonomia, repleta de exigências comunicativas e experimentada intersubjetivamente, dá a direção democrática da experiência educativa. Cabe ao educador apresentá-la e promovê-la.

A tarefa educativa revela, nesse ponto, toda sua complexidade e sutileza. Pois cumpre ao docente direcionar o crescimento da criança, equipando-a cognitivamente, dentro de um universo experiencial. E isso de modo tal que descortine (e não feche) possibilidades de novas e diferentes experiências; estimule (e não negue) significações de que o educando já é capaz, no exercício de seu pensar; promova (e não impeça) a problematização do saber transmitida; abra-se à autonomia do diálogo e não habitue à aceitação passiva e heterônoma de dogmas e doutrinas (DEWEY, 1997, p. 121 e 198; DEWEY, 2010, p. 38 e 39).

Tal atuação docente diretiva não dispensa, portanto, a tarefa expositiva. Aliás, em seu momento inicial, a comunicação, no processo educacional, consiste, basicamente, em transmissão de informações e padrões de comportamento. Trata-se de expediente fundamental para que o educando possa ingressar no universo de linguagem, a partir do que, constituindo sua individualidade, pode pensar e interagir. A finalidade da prática expositiva, enfim, é fornecer material para a reflexão e investigação, e não "pábulo intelectual pronto, a ser aceito e engolido". Tudo isso de modo inversamente proporcional ao crescimento do educando e da autonomia cognitiva e moral por ele adquirida ao longo de sua educação (DEWEY, 1916, p. 11; DEWEY, 1997, p. 198 e 199).

\section{CONCLUSÃO}

A filosofia social deweyana possibilita, dessa forma, hermenêutica jurídica que enriquece de sentidos o conteúdo da educação, concebida como direito fundamental, no âmbito do Estado democrático de direito, também ampliado de significado, unindo-os de forma absolutamente necessária.

Para Dewey, a educação que promove o crescimento do indivíduo não se distingue da formação para a experiência compartilhada da democracia. Trata-se dos aspectos individual e social, absolutamente complementares, da emancipação humana, projetada pelo iluminismo.

O percurso educativo em direção à autonomia passa pelo desenvolvimento de hábitos reflexivos de pensar, agir e conviver, que encontram seu melhor sentido, cognitivo e moral, no discurso que marca a 
democracia. Autonomia moral-cognitivista do indivíduo cola-se à práxis democrática de autodeterminação, de autolegislação.

A formação social da pessoa cria condições para a vida em comum, sem prejuízos à individualidade. A experiência educativa possibilita ao sujeito, dotado da atitude cientifica, no diálogo, e a partir do enfrentamento dos problemas na experiência, a apreensão de seu significado, de modo sempre mais profundo. E isso, na extensão em que, no curso dessa mesma experiência, alarga e reorganiza seu próprio instrumental experiencial e cognitivo. Dessa forma, o sujeito habilita-se, progressivamente, também, à direção e ação reconstrutiva, em comunicação, de suas experiências, em termos objetivos.

"Esparramada" para todos os âmbitos da vida social, a experiência educativa forma o sujeito para o exercício ativo da cidadania, habilitando-o e o dispondo ao enfrentamento de conflitos e demandas sociais, fazendo uso de sua liberdade comunicativa, no espaço público. Assim espraiada, a experiência educativa confundese com a democrática.

O pensamento deweyano deixa claro, por conseguinte, que sem a efetivação da educação, como direito humano fundamental, a democracia e o Estado democrático de direito não podem significar mais do que um aparelho governamental sem lastro num público, uma estrutura jurídico-institucional oca, sem o elemento que the é fundamental, que lhe sustenta e promove continuamente: a dimensão da práxis comunitária, comunicativa de solução compartilhada de problemas de coordenação da ação social.

Educação e democracia configuram, para Dewey, experiências dinâmicas intimamente vinculadas. Uma e outra se pressupõem, refinam-se, enriquecem-se, adensam-se e se reconstroem, continuamente.

\title{
EDUCATION AND DEMOCRACY: EMANCIPATORY PERSPECTIVE FROM JOHN DEWEY'S SOCIAL PHILOSOPHY
}

\begin{abstract}
The purpose of this article is to apprehend the John Dewey's social philosophy as a hermeneutic standpoint for the enriched reading and practice of the human right to education, under the democratic rule of law. To this end, it performs a bibliographical research, reviewing the author's main works on the subject. Within the pragmatist philosophical reconstruction proposal, education and democracy are understood as inseparable communicative experiences. They could perform the emancipation's project of Enlightenment. Beyond the political-institutional dimension, the democracy arises as community experience of solving social conflicts. Education implies the endless process of cognitive and moral growth. It means learning of thinking, acting and living together reflective habits, in dialogical interaction. It involves an educative experience, constituted by the following principles: derivation of the educational content of life experiences; education based on problem solving; progressive development of educational content; dialogical interaction; and pedagogically oriented education. In this way, education leads the individual to moral-cognitive autonomy, and at the same time empowers him to the communitarian and shared experience which characterizes democracy.
\end{abstract}


Keywords: Education, Democracy; discourse; Social philosophy; John Dewey

\section{REFERÊNCIAS BIBLIOGRÁFICAS}

BENJAMIN, Harold. A educação e o ideal democrático. Trad. Beatriz Osório. Série VII - Cursos e conferências Vol. 02. Rio de Janeiro: INEP/MEC, 1960.

BERNSTEIN, Richard J. The resurgence of pragmatism. Social research, vol. 59, nº 4, 1992.

BITTAR, Eduardo C. B. Linguagem Jurídica. 5ª Ed. São Paulo: Saraiva, 2010, p. 142.

BRUBACHER, John S. Importância da teoria em educação. Trad. Beatriz Osório. Série VII - Cursos e conferências Vol. 3. Rio de Janeiro: INEP/MEC, 1961.

CABRAL, Guilherme Perez. Educação para a democracia no Brasil: fundamentação filosófica a partir de John Dewey e Jürgen Habermas. Tese de doutorado. Faculdade de Direito - Universidade de São Paulo. São Paulo, 2014.

DEWEY, John. Democracy and education. An introduction to the philosophy of education. New York: The Macmillan Company, 1916.

The quest for certainty: a study of relation of knowledge and action. New York: Minton, Balch \& Company, 1929.

Experiência e natureza. Trad. Murilo Paes Leme, Anísio S. Teixeira e Leônidas G. Carvalho. Coleção Os Pensadores. São Paulo: Abril Cultural, 1980.

Freedom and culture. Nova York: Prometheus Books, 1989.

The public and its problems. Swallow Press/Ohio University Press/Athens, 1991.

How we think. Mineola, New York: Dover Publications, 1997.

Reconstruction in philosophy. Mineola/New York: Dover Publications, 2004.

O desenvolvimento do pragmatismo americano. Trad. Renato Rodrigues Kinouchi. Scientiae Studia. São

Paulo, v. 5, nº 2, junho/2007. Disponível em: http://www.scielo.br/scielo.php?script=sci_arttext\&pid=S167831662007000200006\&lng= en\&nrm=iso. Acesso em 06/06/2014.

Ethics. The Later Works 1925-1953. Volume 07 (1932). Edited by Jo Ann Boydston. Southern Illinois University, 2008.

Experiência e educação. Trad. Renata Gaspar. Petrópolis/RJ: Vozes, 2010.

FREIRE. Paulo. Pedagogia do oprimido. 50를 ed. Rio de Janeiro: Paz e Terra, 2011.

GADOTTI, Moacir. História das ideias pedagógicas. 8ª ed. São Paulo: Ática, 2002.

GHIRALDELLIJR, Paulo. Filosofia e história da educação brasileira. Barueri: Manole, 2003.

HABERMAS, Jürgen. Direito e democracia: entre factibilidade e validade. Volume 01. $2^{\underline{a}}$ Ed. Trad. Flávio Beno Siebeneichler. Rio de Janeiro: Tempo Brasileiro, 2012.

Direito e democracia: entre factibilidade e validade. Volume 02. Trad. Flávio Beno Siebeneichler. Rio de Janeiro: Tempo Brasileiro, 2011.

HESPANHA, António Manuel. O Caleidoscópio do direito. O direito e a justiça nos dias e no mundo de hoje. $2^{\text {a }}$ 
Ed. Coimbra: Almedina, 2009.

HONNETH, Axel. Democracy as reflexive cooperation: John Dewey and the theory of democracy today. Political Theory, vol. 26, nº 06, Dez/1998

JOAS, Hans. Pragmatism and social theory. Chicago: University of Chicago Press, 1993.

KANT, Emmanuel. Fundamentação da metafísica dos costumes. Lisboa: Edições 70, 2008.

KOHLBERG, Lawrence. La Democracia en la escuela secundaria: educando para una sociedad mas justa. Trad. Maria Oraison. Chaco: Universidad Nacional del Nordeste, 1992.

MEAD, George Herbert. Mind, self and society: from the standpoint of a social behaviorist. Edited by Charles W. Morris. Chicago/London: The University of Chicago Press, 1992.

MENDONÇA, Ana Waleska e outros. Pragmatismo e desenvolvimentismo no pensamento educacional brasileiro dos anos de 1950/1960. Revista Brasileira de Educação, v. 11 nº 31, 2006.

MURARO, Darcísio Natal. Relações entre a filosofia e a educação de John Dewey e a de Paulo Freire. Educação \& Realidade, vol. 38, no 03, jul./set. 2013. Disponível em: http://www.ufrgs.br/edu_realidade. Acesso em 24/06/2014.

ROCHA, Eliezer Pedroso da. O princípio da continuidade e relação entre interesse e esforço em Dewey. Tese (Doutorado - Programa de Pós-graduação em Educação). Faculdade de Educação da Universidade de São Paulo, 2011.

RORTY, Richard. A filosofia e o espelho da natureza. Trad.J. Pires. Lisboa: D. Quixote, 1988.

Consecuencias del pragmatismo. Trad. José M. Cloquell. Madrid: Tecnos, 1996.

TEIXEIRA, Anísio. Dewey e a filosofia da educação. Boletim Informativo CAPES. Rio de Janeiro, n.85, dez. 1959. A pedagogia de Dewey (Esboço da teoria de educação de John Dewey). In DEWEY, John, Experiência e natureza; Lógica: a teoria da investigação; $\mathrm{A}$ arte como experiência; Vida e educação; Teoria da vida moral. Trad. Murilo Paes Leme, Anísio Teixeira e Leônidas G. Carvalho. Coleção Os Pensadores. São Paulo: Abril Cultural, 1980.

TRINDADE, Christiane C. Educação, sociedade e democracia no pensamento de John Dewey. Dissertação (Mestrado - Programa de Pós-graduação em Educação). Faculdade de Educação da Universidade de São Paulo, 2009.

Trabalho enviado em 10 de outubro de 2016.

Aceito em 09 de fevereiro de 2017. 